\title{
Avaliação da aprendizagem no ensino de Física: um olhar sobre as concepçóes dos professores licenciados em Física da cidade de Inhumas, $\mathrm{GO}^{1}$
}

\author{
Raul Isaias Campos* \\ Ivan Carlos Pereira Gomes** \\ Wagner Wilson Furtado***
}

\begin{abstract}
Resumo
O crescente número de trabalhos sobre a avaliação da aprendizagem revela a exigência de reflexôes mais sistemáticas sobre o assunto. Entendendo a necessidade dessa discussão na área de Ciências, o presente artigo apresenta como objetivo principal investigar as concepçóes sobre avaliação de professores de Física em diferentes instituiçóes de ensino na cidade de Inhumas-GO. Para isso, foi feita uma análise qualitativa a partir das respostas dadas em questionários, aplicados a professores de Física de escolas de Ensino Médio da rede pública e privada e de uma instituição pública de Ensino Superior. Os resultados obtidos foram categorizados e demonstraram que a avaliação tradicional ainda prevalece enraizada às concepçôes teórico-filosóficas dos professores.
\end{abstract}

Palavras-chave: avaliaçáo da aprendizagem, avaliação no ensino de Física, concepçôes sobre avaliação.

Assessment of learning in the Physics classroom: a look at the conceptions of Physics teachers in Inhumas, Goiás

\footnotetext{
Abstract

The growing number of studies on the assessment of learning shows a demand for a more systematic reflection on the subject. Understanding the need for such discussion in the field of Science, this article sets out to investigate the assessment conceptions of Physics teachers in different educational institutes in Inhumas, Goiás. To do so, a qualitative analysis was undertaken based on responses to questionnaires administered to Physics teachers in both public and private high schools, and a public institute of higher education. The results were categorized and demonstrated that traditional assessment still prevails ingrained in the theoretical and philosophical conceptions of these teachers.

* Universidade Federal de Santa Catarina/Programa de Pós- Graduação em Educação Científica e Tecnológica. E-mail: icraul@hotmail.com

** Universidade Federal de Goiás/Programa de Mestrado em Educação em Ciências e Matemática. E-mail: ivancpg@yahoo.com.br

*** Universidade Federal de Goiás/Instituto de Física. E-mail: wagner@if.ufg.br
} 
Keywords: learning assessment, assessment in the Physics classroom, conceptions of assessment.

\section{Introduçáo}

As instituiçóes de ensino, como parte constituinte da sociedade, refletem entre seus muros as várias formas de exclusão social. Os diferentes posicionamentos teórico-filosóficos assumidos pelos professores acabam ratificando a discriminaçáo e a seletividade na escola (CHAVES, 2003). O local que deveria proporcionar ao sujeito o acesso aos conhecimentos edificados pelo homem, durante séculos, acaba ceifando esta oportunidade e parte da população deixa de exercer a cidadania de uma forma mais crítica e consciente.

Paulo Freire (2010, p. 68), ao discutir esta postura tradicional de ensino, afirma que "o educador é o que diz a palavra e os educandos, os que a escutam docilmente; [...] o educador é o sujeito do processo e os educandos, meros objetos". Para ele, o que ocorre, em geral, é uma "educação bancária", na qual o aluno é um mero receptáculo, pronto para, quando exigido, apenas expelir os conteúdos acumulados.

No intuito de compreender esse processo de exclusão gerado dentro da escola, o tema avaliação se torna relevante. Nota-se que as atividades avaliativas tradicionais, voltadas apenas para a aprovaçáo e reprovaçáo, ou seja, de caráter autoritário e especificamente classificatório, estão inseridas no ensino como partes de uma "educação bancária" e, de uma forma mais geral, inseridas no interior de uma sociedade desigual.

A fim de repensar esse posicionamento, observa-se que um número crescente de estudos sobre a avaliação da aprendizagem escolar vem evidenciando a relevância de se discutir as práticas avaliativas no processo educativo. No Brasil, por exemplo, tem-se falado em avaliação mediadora, avaliação formativa, avaliação dialógica e avaliação diagnóstica, propostas críticas que se desenvolvem em contrapartida aos modelos tradicionais de avaliação (VILLAS BOAS, 2010).

Vale ressaltar que existem diferenças pontuais e específicas de cada proposta de avaliação, mas pode-se observar também que todas possuem uma mesma origem. Surgem para desfazer a ideia de que avaliar tenha a simples finalidade de quantificar o conhecimento adquirido, privilegiando a memorização em detrimento da real aprendizagem. Nesse caso, para que 
fique mais claro, torna-se necessário destacar os pontos importantes de cada proposta.

Ao se falar em avaliação mediadora, faz-se necessário pensar em uma ação avaliativa que visa a investigar e a acompanhar de forma cotidiana o processo de aprendizagem. Por meio da análise de tarefas de maneira extensiva, a avaliação mediadora busca sempre interpretar e compreender o desempenho escolar do estudante, para que o ato de aprovar ou reprovar náo seja apenas embasado em um juízo isolado, como em uma prova final, mas na história da produção de conhecimento do aluno (HOFFMANN, 1998).

Já a proposta formativa coloca a avaliação a serviço da aprendizagem, ato que se dá pela necessidade de uma intervençáo, para que se identifique e conheça o que o aluno já aprendeu e o que ele ainda não aprendeu, a fim de que se providenciem os meios necessários à continuidade dos seus estudos. Dessa forma, é necessário haver tempo para sanar as dificuldades assim que elas apareçam. Se isso não for possível, a ideia de uma avaliação formativa perde seu sentido (PERRENOUD, 1999).

Ao encontro dos dois modelos já citados, tem-se a avaliação dialógica. Trata-se de uma concepçáo de avaliaçáo que deixa de ser verificacionista e que passa a ter a avaliação como um momento de aprendizagem, sempre intercedida pelo diálogo entre o professor e o aluno. Nessa perspectiva, segundo Romão (2005), alguns passos para a execução de uma avaliação dialógica são importantes: a identificação do que vai ser avaliado; a constituição, a negociação e o estabelecimento de padrôes de avaliação; a construção de instrumentos de medida e de avaliação; a determinação do procedimento de medida e da avaliaçáo; a análise do resultado e tomada de decisão.

E ainda, em direção às propostas de uma avaliação crítica, tem-se também a avaliação diagnóstica. Luckesi (2006, p. 28), ao tratar desta concepção, afirma que "a avaliação não se dá nem se dará num vazio conceitual, mas sim dimensionada por um modelo teórico de mundo e de educação, traduzido em prática pedagógica”. Ou seja, a avaliação diagnóstica não é amparada por conceitos neutros e, se assim for justificada, não avança na construção de uma escola mais democrática e, por conseguinte, colabora para a manutenção do status quo.

No ensino de Física, a avaliaçáo da aprendizagem ainda não tem a atenção necessária. Observamos que nele as práticas avaliativas ficam restritas às análises quantitativas. A riqueza de conceitos físicos que permeiam os 
conteúdos, tanto da educação básica quanto da educação superior, não são suficientes para que haja uma mudança substancial nas avaliaçóes, repletas de exercícios desvinculados da realidade e das correçóes que se limitam à análise numérica.

Diante disso, este artigo busca compreender a concepção de professores sobre a avaliação e discute o posicionamento destes à luz de uma teoria embasada na ideia de uma avaliação diagnóstica. Para isso, tem-se como objetivo investigar as concepçóes sobre avaliação dos professores licenciados em Física das instituiçóes de ensino em Inhumas, GO.

\section{Fundamentaçáo teórica}

Na busca de práticas avaliativas inclusivas, que visem à transformação social, a avaliação diagnóstica surge como alternativa. Sobre esta prática, Luckesi (2006) afirma:

A avaliação deverá ser assumida como um instrumento de compreensão do estágio de aprendizagem em que se encontra o aluno, tendo em vista tomar decisóes suficientes e satisfatórias para que possa avançar no seu processo de aprendizagem. Se é importante aprender aquilo que se ensina na escola, a função da avaliação será possibilitar ao educador condições de compreensão do estágio em que o aluno se encontra, tendo em vista poder trabalhar com ele para que saia do estágio defasado em que se encontra e possa avançar em termos de conhecimentos necessários. (LUCKESI, 2006, p. 81)

Para o autor, a avaliação deixa de ser um instrumento pontual e necessariamente determinante na aprovaçáo ou reprovaçáo e se torna um instrumento diagnóstico, ao fazer encaminhamentos sobre a aprendizagem dos alunos. A avaliação, assim, tem o objetivo de incluir ao invés de excluir.

$\mathrm{O}$ que se percebe, entretanto, é que a avaliação ainda tem como finalidade quantificar o conhecimento adquirido, pois o sistema de ensino exige uma classificação para efetivar os registros que indicarão uma aprovação ou reprovação. Conforme Luckesi (2005, p. 15), o que o professor pratica, nesse caso, são "exames escolares". A nota obtida pelo aluno torna-se um motivo de aprovação em um sistema que privilegia a memorizaçâo em detrimento da real aprendizagem.

Hoje, o exercício pedagógico está centrado mais em uma pedagogia do exame do que em uma pedagogia do ensino e aprendizagem. E isso pode 
ser justificado pelas diversas demandas a que a escola é submetida, a saber: o sistema, ao se preocupar com o número de aprovados e reprovados; os pais, ao se interessarem pelo avanço dos filhos nas séries; e os professores, ao utilizarem a prova como instrumento de ameaça e coerção (LUCKESI, 2006).

Além dessas demandas, o alto índice de evasão e reprovação, atingindo sobretudo as camadas populares, faz com que Dalben (2002, p. 17) apresente alguns conflitos surgidos no campo da avaliação, tais como as discussóes em torno da democratização da escola pública e a elaboração da legislação específica. Entretanto, os encaminhamentos deste debate sobre as políticas públicas de avaliação tomaram sentidos contrários, pois são amparados em bases político-pedagógicas diferentes.

Como uma característica das últimas décadas da educação brasileira, a escola ampliou suas vagas e permitiu o ingresso de pessoas que antes não tinham essa oportunidade. A universalização do acesso à escola trouxe a diversidade populacional para dentro dela e, portanto, deve-se encontrar formas de avaliar esses novos alunos que se desenvolveram em diferentes contextos culturais, com diversos tipos de acesso à informação e com níveis variados de desenvolvimento.

Outra discussão que toma rumos singulares é aquela que vai se firmar a partir das políticas públicas do governo federal, por meio da Lei de Diretrizes e Bases da Educação Nacional (BRASIL, 1996). Na legislação, a avaliaçáo passa a ser um instrumento fiscalizador do Estado, ou seja, "ele se transforma em um avaliador externo, com o papel de monitorar, credenciar e oferecer indicadores de desempenho para os sistemas de ensino do país" (DALBEN, 2002, p. 18). Enquanto a escola se democratiza, o Estado se coloca como potencial algoz.

Como alternativa de superar os múltiplos dilemas surgidos a partir desses encaminhamentos, muitas vezes contraditórios, Luckesi (2006) faz algumas proposiçóes para o desenvolvimento da avalição diagnóstica - um modelo que prestigia tanto o acesso e a continuidade dos estudos quanto a qualidade do ensino, sujeita às condições impostas pelo Estado.

Em primeiro lugar, a mudança de utilização da avaliação classificatória para a diagnóstica. A avaliação deve ser assumida para a democratização do ensino e como "compreensão do estágio de aprendizagem em que se encontra o aluno, tendo em vista tomar decisóes suficientes e satisfatórias para que possa avançar no seu processo de aprendizagem" (LUCKESI, 2006, p. 81). 
A avaliação então se torna um instrumento auxiliar na aprendizagem e não um mecanismo que delibera unicamente sobre a aprovação ou reprovação dos alunos.

Um outro ponto importante é que a avaliação deve ser comprometida com uma cencepção pedagógica, pois esta é uma das condiçôes de sua existência. No caso da avaliação diagnóstica, Luckesi assume uma concepção progressista, denominada pedagogia histórico-crítica. Nesta perspectiva, o aluno se apropria do conhecimento construído e atua como sujeito crítico na sociedade em que vive (LUCKESI, 2006).

\section{Os caminhos da pesquisa}

Como nossa intenção foi analisar as concepções de avaliação de professores, optamos pela abordagem qualitativa, visto que ela possibilita um conhecimento mais profundo do contexto escolar, o qual não se deixa apreender somente por descriçóes matemáticas (métodos quantitativos) e que ainda permite descobrir novos conceitos, novas relaçóes, novas formas de entendimento da realidade, novas formas de pensar e de agir (TRIVIÑOS, 2008).

A pesquisa foi realizada por meio de questionários aplicados a quatro professores licenciados em Física do município: três do Ensino Médio e um do Ensino Superior.

Para realizar a investigação, optou-se por elaborar questionários com questóes abertas, pois acredita-se que eles possibilitam ao respondente maior liberdade ao representar pela escrita suas ideias e reflexóes. Posteriormente, foi feito o tratamento do material: tabularam-se as respostas obtidas nos questionários e fez-se uma releitura de todo o material para selecionar os dados a serem apresentados e analisados. Depois, identificaram-se os dados relevantes para o trabalho.

\section{Resultados e análises}

Apesar de o questionário aplicado aos professores conter 6 questóes abertas, selecionaram-se algumas respostas consideradas pertinentes para as análises desejadas neste trabalho. A fim de preservar o anonimato das pessoas pesquisadas, suas manifestações transcritas estão individualizadas por meio de sua função, Professor, seguido de um número. 
Ao serem perguntados sobre o que entendem por avaliação da aprendizagem escolar, os professores responderam:

a) Entendo que é uma maneira de verificar o aprendizado do aluno. (Professor 1).

b) Um grupo de ações elaboradas pelo professor para que o aluno possa apresentar o quanto consegue absorver. (Professor 2)

c) É uma forma do aluno transmitir seu conhecimento adquirido do conteúdo selecionado. (Professor 3)

d) A avaliação da aprendizagem é um componente do processo que visa verificar os resultados obtidos, determinar e orientar as decisôes em relação às atividades didáticas seguintes. (Professor 4)

Analisando essas respostas, verificamos que a fala do Professor 1 indica que ele possui uma concepção pedagógica limitada sobre o papel da avaliação. Já a resposta do Professor 2 indica que sua concepção de avaliação se aproxima bastante da ideia de "educação bancária". Para ele, a avaliação serve para verificar quanto o aluno apreendeu em determinado conteúdo, estudado.

Vemos, também, que o Professor 3 possui valores enraizados ao modelo tradicional de avaliação: transmissão-recepção-confirmação. Para ele, a avaliação tem a função de finalizar o aprendizado, ou seja, ela é uma atividade conclusiva, não dá oportunidade para incluir o aluno que não tenha atingido uma aprendizagem satisfatória. Já o Professor 4 aparenta maior conhecimento da função da avaliação no processo ensino e aprendizagem.

Ao lermos outras respostas, vale ressaltar, constatamos que o Professor 1 avalia constantemente seus alunos, mesclando instrumentos quantitativos e qualitativos, tais como seminários, trabalhos em grupo e atividades extraclasses. Ao ser questionado por que utiliza esse modelo de avaliação, ele respondeu:

Para aproveitar tudo de bom do aluno e para aumentar a autoestima de cada um. (Professor 1)

Analisando agora a sua fala, observamos que o professor demonstra valorizar o comportamento e o desenvolvimento de seus alunos, e tenta náo tratar a avaliação como um acerto final de contas, apenas usada para aprovar e reprovar. 
Questionado quanto a função da avaliação, a opinião do Professor 1 é bem ampla e difusa, como podemos observar em seu relato:

Preparar o aluno a viver socialmente, fazer concurso, prestar vestibular e prepará-lo para viver o mundo de hoje. (Professor 1)

Já para o Professor 4, a função da avaliação é:

Comprovar a aprendizagem e diagnosticar o progresso e dificuldade do educando. (Professor 4)

Essa resposta mostra que esse professor considera a avaliaçáo importante para o diagnóstico de dificuldades do estudante e para a reorientação de atividades futuras.

Ao questionarmos os professores sobre quais as suas maiores dificuldades ao avaliar, o Professor 2 atribui a responsabilidade aos estudantes:

Nossos alunos, cada ano que passa, não se empenham como deveriam. Isto proporciona um aprendizado fraco e desmotivador. (Professor 2)

Percebe-se que esse professor considera que os problemas da aprendizagem em Física se devem à disposição, quase exclusiva, do aluno, e se isenta de responsabilidades. A citação de McLuhan se torna significativa neste caso, pois, para ele, "o professor é o único profissional cujo fracasso é atribuído, automaticamente, às suas vítimas: se o aluno não aprende é que não estudou, jamais é culpa do professor" (MCLUHAN apud DEMO, 1981, p. 70). É contraditório pensar em aprendizagem desmotivadora sem relacionar as atitudes referentes ao ato de ensinar. Vale ressalvar que o Professor 2 leciona em uma instituição que oferece um bom plano de carreira, bons salários, boa infraestrutura e baixa carga horária de aulas.

Verificamos que o Professor 3 utiliza, com maior frequência, provas e listas de exercícios como instrumentos avaliativos. Ele justifica esse procedimento pela condição a que é submetido profissionalmente:

É a forma imposta pelo Colégio e pela Secretaria da Educação. (Professor 3)

De acordo com esse relato, as práticas avaliativas são limitadas e estabelecidas por exigências externas. Como esse colégio tem como objetivo preparar os alunos para o ingresso no Ensino Superior público, os próprios 
modelos dos vestibulares interferem diretamente nas atividades de ensino, de aprendizagem e nas práticas avaliativas.

\section{Consideraçóes finais}

A concepção de avaliação da maioria dos professores pesquisados é centrada na classificação, ou seja, uma avaliação apenas somativa: o professor elabora as avaliaçóes - usam com maior frequência provas escritas - e no final liberam o resultado. É sabido que só esse tipo de avaliação não afere todos os progressos que o aluno alcançou, como mudança de atitudes, envolvimento e crescimento no processo ensino e aprendizagem.

Nos casos estudados, apenas um dos professores tem a concepção de avaliação como um diagnóstico da aprendizagem. Talvez, os indicativos desse fato isolado sejam a excessiva carga horária de trabalho e as numerosas turmas dos outros professores. Dessa forma, compromete-se a reflexão sobre a aprendizagem dos alunos, e a ideia de uma avaliação diagnóstica, que se fundamenta no diálogo necessário e possível entre alunos e professores, não se concretiza.

Percebe-se, também, que mesmo o professor que possui o maior salário e a menor carga horária pratica uma avaliação considerada tradicional. A sua postura é diferente da que Cunha (2009) verificou em seu trabalho, no qual pesquisou as práticas avaliativas de professores de Matemática de diferentes instituiçôes de ensino (colégios estaduais, federais e particulares de Ensino Médio), em Goiânia, GO:

Vimos que alguns, apesar de se preocuparem com o processo ensino e aprendizagem e até tentarem realizar uma avaliaçáo formativa, são impedidos de realizar totalmente tal tipo de avaliaçáo, devido a esse excesso de trabalho. Afirmamos isso com convicção, pois observamos que os professores que possuem uma carga horária didática menor e melhores salários, além de uma melhor formação, se dedicam a pensar o ensino e a aprendizagem e utilizam instrumentos de avaliaçâo que possuem características formativas, além de que conseguem fazer um trabalho diferenciado. (CUNHA, 2009, p. 63)

Assim, a postura dos professores pesquisados mostra a necessidade de uma continuidade dos estudos, seja ela feita em cursos de pós-graduação stricto sensu ou lato sensu. No caso dos professores das instituiçóes públicas, 
um plano de carreira que incentivasse esse aprimoramento seria muito importante.

Outro ponto relevante foi que os professores pesquisados mencionaram a falta de atividades de laboratório e de outros recursos didáticos nas escolas, demonstrando que tais recursos poderiam oferecer uma forma diferenciada $\mathrm{e}$ mais crítica da avaliação. Vale ressaltar que, no caso da Física, é inconcebível que instituiçóes de ensino, especialmente de nível técnico e superior, não possuam laboratórios de ensino. Por ser uma ciência experimental, seu ensino deve estar acompanhado de práticas experimentais. Ela não deveria ser entendida como um método para resolver problemas numéricos teóricos, mas sim como uma ciência fundamentada em pesquisas e conceitos e que possui, em suas bases, leis fortemente estruturadas.

Assim, diante dos dados, percebe-se que a maioria dos professores pesquisados mantém uma atitude profissional de certa forma conservadora, sendo o modelo de avaliação uma reflexão de suas aulas e ideias. Com esse trabalho, espera-se levar a professores e educadores a grande problemática existente em suas práticas avaliativas, pois não se notou, nas concepçóes desses professores, pelo menos na maioria, nem ao menos tênues traços ou tendências dos modelos de avaliação mediadora, formativa, dialógica ou diagnóstica. Embora a pesquisa tenha sido realizada em uma cidade pequena, presume-se que a postura tradicional avaliativa reconhecida nos sujeitos dessa pesquisa esteja presente também em grande parte das escolas brasileiras.

Nota

1. A ideia preliminar deste trabalho foi apresentada no XIX Simpósio Nacional de Ensino de Física (XIX SNEF), Manaus, AM, em 2011, com o título "Avaliação da aprendizagem no ensino de Física: um olhar sobre as práticas escolares na cidade de Inhumas, GO".

\section{Referências}

BRASIL. Lei de Diretrizes e Bases da Educação Nacional: Lei n. 9.394/1996. Disponível em: <http://portal.mec.gov.br/arquivos/pdf/ldb.pdf>. Acesso em: 15 abr. 2012. 
CHAVES, Sandramara Matias. Avaliação da aprendizagem no ensino superior: realidade, complexidade e possibilidades. Tese (Doutorado em Educação) Faculdade de Educação, Universidade de São Paulo, São Paulo, 2003.

CUNHA, Maria Francisca. Desvendando as práticas avaliativas de professores de Matemática em turmas do $1^{\circ}$ ano do ensino médio da cidade de Goiannia. 93 f. Dissertação (Mestrado) - Universidade Federal de Goiás, Programa de Pós-Graduação em Educação em Ciências e Matemática, Goiânia, 2009.

DALBEN, Ângela I. L. de Freitas. Das avaliações exigidas às avaliaçóes necessárias. In: VILLAS BOAS, Benigna M. de F. (Org.). Avaliação: políticas e práticas. 3. ed. Campinas: Papirus, 2002.

DEMO, Pedro. Metodologia cientifica em Ciências Sociais. 1. ed. Sáo Paulo: Atlas, 1981.

FREIRE, Paulo. Pedagogia do oprimido. Sáo Paulo: Paz e Terra, 2010. 49a reimpressão.

HOFFMANN, Jussara Maria Lerch. Pontos e contrapontos: do pensar ao agir em avaliação. Porto Alegre: Mediação, 1998.

LUCKESI, Cipriano Carlos. Avaliação da aprendizagem na escola: reelaborando conceitos e recriando a prática. 2. ed. rev. Salvador: Malabares, 2005.

LUCKESI, Cipriano Carlos. Avaliação da aprendizagem escolar. 18. ed. São Paulo: Cortez, 2006.

PERRENOUD, Philippe. Avaliação: da excelência à regulação das aprendizagens: entre duas lógicas. Porto Alegre: Artes Médicas Sul, 1999.

ROMÃO, José Eustáquio. Avaliação dialógica: desafios e perspectivas. 6. ed. São Paulo: Cortez, 2005.

VILLAS BOAS, Benigna Maria de Freitas. Portfólio, avaliação e trabalho pedagógico. 7. ed. Campinas, SP: Papirus, 2010.

TRIVIÑOS, Augusto Nibaldo Silva. Introdução à pesquisa em ciências sociais: a pesquisa qualitativa em educação. São Paulo: Atlas, 2008.

Recebido em 12 jun. 2012

Aceito em: 25 set. 2012 
